\title{
BMJ Open Areca nut consumption with and without tobacco among the adult population: a nationally representative study from India
}

\author{
Prashant Kumar Singh (D) , ${ }^{1,2}$ Amit Yadav, ${ }^{3}$ Lucky Singh, ${ }^{4}$ Sumit Mazumdar (D) , ${ }^{5}$ \\ Dhirendra N Sinha, ${ }^{6}$ Kurt Straif, ${ }^{7,8}$ Shalini Singh ${ }^{2,9}$
}

To cite: Singh PK, Yadav A, Singh L, et al. Areca nut consumption with and without tobacco among the adult population: a nationally representative study from India. BMJ Open 2021;11:e043987. doi:10.1136/ bmjopen-2020-043987

- Prepublication history and supplemental material for this paper is available online. To view these files, please visit the journal online (http://dx.doi. org/10.1136/bmjopen-2020043987).

Received 20 August 2020 Accepted 19 April 2021

Check for updates

(C) Author(s) (or their employer(s)) 2021. Re-use permitted under CC BY-NC. No commercial re-use. See rights and permissions. Published by BMJ.

For numbered affiliations see end of article.

Correspondence to Dr Prashant Kumar Singh; prashants.geo@gmail.com

\section{ABSTRACT}

Objective Areca nut is one of the most widely consumed substances globally, after nicotine, ethanol and caffeine and classified as carcinogenic to humans. This study examines the disparity and determinants of areca nut consumption with and without tobacco in India.

Design Nationally representative cross-sectional study. Participants We used the nationally representative Global Adult Tobacco Survey 2016-2017. The analytical sample size was 74037 individual's aged 15 years and above with a response rate of $92.9 \%$.

Measures Current consumption of areca nut without tobacco and with tobacco.

Method We examined determinants of areca nut consumption (without tobacco and with tobacco) using multinomial logistic regression, accounting for the survey design.

Results About $23.9 \%$ (95\% Cl 23.1 to 24.8 ) of the adult population consume areca nut, that is, approximately 223.79 million people in India; majority of users (14.2\%$95 \% \mathrm{Cl} 13.5$ to 14.9 ) consumed areca nut with tobacco. When compared with women, men were more likely to consume areca nut (with tobacco relative risk $(\mathrm{RR})=2.02$; $95 \% \mathrm{Cl} 1.85$ to 2.21 and without tobacco $\mathrm{RR}=1.13 ; 95 \% \mathrm{Cl}$ 1.07 to 1.20). Age, marital status, education, occupation, caste, religion and region were significantly associated with areca nut consumption. However, the direction and magnitude of association differ with respect to the areca nut consumption with and without tobacco.

Conclusion The ongoing tobacco control efforts would not address the majority of areca nut users until greater attention to areca nut consumption with and without tobacco is reflected in health policies in India.

\section{INTRODUCTION}

Areca nut is one of the most widely consumed substances globally, after nicotine, ethanol and caffeine. ${ }^{12}$ Owing to its addictive properties, areca nut is estimated to be consumed by hundreds of millions of people across various countries. ${ }^{3}$ However, addiction to areca nut is primarily prevalent in many Asia-Pacific countries and by emigrants from these countries in other parts of world. ${ }^{3}$ It is not only known
Strengths and limitations of this study

- Using a nationally representative survey with a high response rate, this study disentangled the current prevalence of areca nut consumption with and without tobacco in India, which has significant policy implications.

- The study provided detailed information on socioeconomic determinants of areca nut consumption, with and without tobacco, and separately for men and women, which may further guide future policy.

- The survey covers only people 15 years and older, whereas areca nut consumption often starts at younger age.

- The survey cannot provide insights into trends of areca nut consumption over time.

by several, sometimes local names, but also consumed in several forms, for example, pan masala, gutkha, mawa, dohra, kharra, betel and so on with or without tobacco. ${ }^{45}$ Some forms of consumption may also include other constituents, such as betel leaf, slaked lime and various spices.

The International Agency for Research on Cancer classified area nut consumption with or without tobacco as carcinogenic to humans. ${ }^{6}$ A meta-analysis based on 50 studies worldwide reported increased relative risks for cancer of the oral cavity and oropharynx for the Indian subcontinent and areca nut consumption with tobacco (Relative Risk 7.03; $95 \%$ CI 4.68 to 10.56 ) and areca nut consumption without tobacco (Relative Risk 3.22; $95 \%$ CI 2.11 to 4.92$).{ }^{7}$ A global systematic review based on 62 studies concluded that consumption of areca nut affects almost all organs of the human body, including the brain, heart, lungs, gastrointestinal tract and reproductive organs; and causes or aggravates pre-existing conditions such as neuronal injury, myocardial infarction, cardiac 
arrhythmias, hepatotoxicity, asthma, central obesity, type II diabetes, hyperlipidaemia, metabolic syndrome. ${ }^{8}$ It has harmful effects on the fetus when used during pregnancy. ${ }^{8}$ Previous studies observed that areca nut dependency among users ${ }^{9}$ and its withdrawal effects ${ }^{10}$ were similar to those observed among nicotine users. ${ }^{10} \mathrm{It}$ is also a gateway product in children who start using different kinds of areca nut products at an early age. ${ }^{11}$

Despite growing scientific evidence of high addictiveness and several ill effects (8-11) associated with areca nut consumption, research on areca nut has not received much attention. ${ }^{3}$ The large global and national movement that addresses tobacco control under the ambit of the WHO Framework Convention on Tobacco Control (FCTC) has focused primarily on smoking and has been less effective in controlling smokeless tobacco (SLT). ${ }^{12}$ The regulatory framework for areca nut control has also remained limited to prescribing health warnings on areca nut products by the Food Safety and Standard Authority of India. Furthermore, use of tobacco and nicotine as an ingredient in any food item is also prohibited under FSSA regulations, thereby restricting mixing of tobacco in areca nut products and vice versa. ${ }^{1}$ Although tobacco control policies are applicable to areca nut products which contain tobacco a considerable number of people now consume areca nut without tobacco, which poses greater public health challenges in controlling and regulating the substance. ${ }^{13}$

A comprehensive search of the literature revealed that studies on areca nut use in India lack representativeness and published studies were restricted to a specific geographical area or population groups. None of the published studies have examined diverse habits of areca nut consumption, its disparity and determinants using a nationally representative survey. Also, a recent global review calls for more research to better understand the epidemiology of areca nut consumption across different populations and geographies. ${ }^{3}$

India, with a population of over 1.30 billion, exhibits one of the highest socioeconomic and demographic heterogeneities ever experienced anywhere in the world at the regional level. ${ }^{14}$ There is considerable evidence of marked regional inequities in tobacco use ${ }^{15}$ health and healthcare $^{16}$ and mortality outcomes ${ }^{17}$ in India. These differences are primarily the outcomes of differences in community-level development, population composition, state health expenditure, poverty levels, status of women and availability, accessibility and affordability of maternal and child healthcare services and their utilisation. ${ }^{18-20}$

While India's share to overall areca nut production and consumption remains at the top in the world, no attempts have been made to explore the patterns and determinants of the consumption of areca nut based on largescale representative surveys. This study aims to examine the disparity and determinants of areca nut consumption, with and without tobacco using the nationally representative Global Adult Tobacco Survey (GATS) conducted in 2016-2017.

\section{METHODS AND MATERIALS}

\section{Study design and participants}

We used the nationally representative cross-sectional GATS 2016-2017, conducted in all 29 states and three union territories (UTs) of India. ${ }^{21}$ The study included whole GATS sample of 74037 adults aged 15 and above. A multistage sampling design separately for rural and urban areas was adopted to draw a representative sample considering the 2011 census population figures. The personlevel response rate was $96.0 \%$ (95.6\% in urban areas and $96.3 \%$ in rural areas). The overall response rate, calculated as the product of response rates at the household and person level, was $92.9 \%$.

The sampling was done independently in each state/ UT; and within the state/UT, it was done independently for urban and rural areas. In urban areas, a three-stage sampling process was adopted. At the first level, the list of all the wards from all cities and towns of the state/ UT constituted the urban sampling frame, from which a required sample of wards (primary sampling unitsPSUs) was selected using probability proportional to size (PPS) sampling. At the second level, a list of all census enumeration blocks (CEBs) in each selected ward constituted the sampling frame from which one CEB was selected by PPS from each ward. At the third level, a list of all residential households in each selected CEB constituted the sampling frame, from which a sample of required number of households was selected.

In rural areas, a two-stage sampling process was adopted. At the first stage of sampling, all villages in the state/UT formed the sampling frame. All small villages having less than five households were removed from the sampling frame. Villages with 5 to 49 households as per Census of India, 2011 were linked with the neighbouring larger villages. The required number of PSUs (villages) within each stratum was selected according to PPS sampling. At the second stage, a list of all residential households in each selected village constituted the sampling frame, from which a sample of the required number of households was selected.

A household listing operation was carried out in each sample area. All large villages with 300 or more households were segmented into three or more segments (depending on village size) of almost equal proportions, each being about 100-200 households. From all the segments in each large village, two segments were selected by using PPS sampling. Thirty households (plus three more, accounting for nonresponse) were selected from the list of households by systematic random sampling. The 33 selected households in a PSU were divided into two groups: (1) households for interview of a male member and (2) households for interview of a female member; this was in proportion to the total sample size of male and female interviews in a state. From the total number of male/female members aged 15 or above in a household, one member was randomly selected for the interview.

Further details related to survey methodology, sampling design, household and individual selection, 
data collection, management and monitoring procedures have been described elsewhere. ${ }^{21}$

\section{Dependent variables}

The outcome variable was current consumption of areca nut use, assessed based on the following questions covered in the GATS:

i. Do you consume pan masala without tobacco? (response options: yes, no and refused)

ii. Do you consume betel quid without tobacco? (response options: yes, no and refused)

iii. Do you consume areca nut of any type, plain, powdered or flavoured? (response options: yes, no and refused)

iv. Betel quid with tobacco? (response: on average, how many times a day do you use).

v. Gutka, areca nut-tobacco lime mixture, or mawa? (response: on average, how many times a day do you use)

vi. Pan masala with tobacco? (response: on average, how many times a day do you use).

Based on the above-mentioned questions asked in GATS, we constructed three sets of variables: (1) areca nut consumption only without tobacco, (2) areca nut consumption only with tobacco and (3) areca nut consumption with and without tobacco, dual use. Definition of specific products can be found with the GATS two national report. ${ }^{22}$

\section{Independent variables}

A range of socioeconomic (education, occupation, caste, religious affiliation and wealth quintile), demographic (age, sex, marital status), awareness-related and contextual level variables included in this study, which were found to be associated with areca nut consumption in previous studies. ${ }^{23-27}$ These variables include age (categorised as 15-18, 19-23, 24-30, 31-40, 41-50, 51-60 and $60+)$ and sex as male and female. Individual's education was measured as: (1) no formal education, (2) below primary, (3) primary completed, (4) below secondary, (5) secondary completed, (6) completed higher secondary, (7) completed college/university and (8) completed postgraduate level. Individual's occupation on the other side was assessed based on self-reported information as (1) student, (2) government sector, (3) nongovernment sector, (4) casual/daily labourer, (5) self-employed, (6) homemaker, (7) retired and (8) unemployed.

A wealth index was calculated based on availability of electricity, flush toilet, radio, television, fixed telephone or cell phone, refrigerator, washing machine, moped/ scooter/motorcycle and car using principal component analysis (PCA) methodology. ${ }^{28}$ There are various ways to assign weighting values to the indicator variables. Ad hoc weights, such as assigning ' 1 ' for a bicycle, ' 3 ' for a motorcycle and ' 5 ' for a car or truck, work to a certain extent, but they are arbitrary and are difficult to assign when the wealth ordering is not readily apparent. For this reason, Filmer and Pritchett recommended using PCA to assign the indicator weights, the procedure that is used for the wealth index. ${ }^{29}$ This procedure first standardises the indicator variables (calculating $\mathrm{z}$ scores); then the factor coefficient scores (factor loadings) are calculated and, finally, for each household, the indicator values are multiplied by the loadings and summed to produce the household's index value. In this process, only the first of the factors produced is used to represent the wealth index. The resulting sum is itself a standardised score with a mean of 0 and an SD of $1 .^{28}$ Individuals were divided into five wealth quintiles based on their household score ranges from 1 being poorest to 5 being wealthiest, with each category representing $20 \%$ of the score. ${ }^{28}$

A composite knowledge variable, which measures the poor health impact of SLT use, was constructed based on the following information asked in the survey: SLT causes serious illness (yes/no), SLT causes oral cancer (yes/no), SLT causes dental diseases (yes/no), SLT causes harm to fetus during pregnancy (yes/no) and do you think SLT leads to addiction (yes/no). The new knowledge variable was categorised as: (1) 'no, to all five awareness', (2) 'no, to at least one awareness' and (3) 'yes, to all five awareness'.

Caste (social group) as categorised based on individual's self-reporting as Scheduled Castes (SCs), Scheduled Tribes (STs), Other Backward Classes (OBCs) and others. This broad categorisation of caste is based on their socioeconomic disadvantage in education, health, nutrition and employment by federal government. For instance, a study has shown that as compared with other caste, children (age 2-5 years) and adolescents (age 6-18 years) belonging to STs had the greatest risk of mortality ( $\mathrm{OR}=1.94,95 \%$ CI 1.47 to 2.57), followed by those from SCs $(\mathrm{OR}=1.35,95 \%$ CI 1.05 to 1.74$)$ and $\mathrm{OBCs}(\mathrm{OR}=1.33$, $95 \%$ CI 1.05 to 1.67$).{ }^{17}$ Other studies have also shown lower enrolment and completion of education among SCs and STs due to various factors. ${ }^{30}{ }^{31}$ Religion captures self-reported follower/believer of Hinduism, Islam, Christianity and others (which mainly include Sikhs, Jains, Buddhists and nonbelievers). The study also considered place of residence as rural and urban as well as all 29 states and three UTs in the analysis.

\section{Analytical strategy}

At first, prevalence of areca nut consumption with and without tobacco at national and subnational levels along with rural-urban and male-female differences was analysed. $\chi^{2}$ tests were performed to examine whether variations in areca nut consumption across independent variables were statistically significant. To examine the associated between areca nut consumption with various socioeconomic and demographic characteristics, multinomial logistic regression was used. In the multinomial logit regression, it is assumed that log odds of outcome/ dependent variable either follow linear form or non-binary form; each outcome/dependent variable is modelled relative to the baseline group or outcome. ${ }^{32}$ In this study, we have considered (1) 'non-areca nut user (baseline group)', (2) 'areca nut consumption only with tobacco', 
(3) 'areca nut consumption only without tobacco' and (iv) 'areca nut consumption with and without tobacco, dual use'. The study reported the relative risk ratio along with $95 \%$ CIs. ${ }^{33}$ We calculated the population burden based on GATS weighted sample population figures, which were provided in the GATS India report. ${ }^{22}$ The analysis was adjusted for sampling weights and multistage sampling design using syv command in STATA. Analysis was carried out in STATA, V. $15^{34}$

\section{Patient and public involvement}

No patients were involved in the development of the research question, the outcome measures or the design of the study.

\section{RESULTS}

\section{Descriptive statistics}

Of the 74037 respondents, $40265(48.9 \%)$ were women and $33772(51.1 \%)$ were men and $47549(65.5 \%)$ individuals resided in rural areas. One out of four respondents had no formal education and nearly $78 \%$ were aware about the adverse health effects of SLT consumption (online supplemental table 1).

We found that overall, betel quid without tobacco (8.7\%; 95\% CI 6.7 to 10.2$)$ was consumed largely, followed by areca nut of any type (8\%; 95\% CI 5.9 to 10.3 ) at the national level (table 1). Among men, the prevalence of gutka, areca nut-tobacco lime mixture or mawa was consumed the most (17.8\%; 95\% CI 15.1 to 20.2), whereas, among women, betel quid without tobacco was largely consumed $(9.0 \%$; $95 \%$ CI 6.1 to 11.9$)$. In urban areas, both betel quid without tobacco and areca nut of any type were largely consumed, while in the rural areas, it was mainly betel quid without tobacco. Regional pattern suggests that betel quid with tobacco was predominately consumed in many north-eastern states, while betel quid without tobacco was mainly used in south (online supplemental table 2).

\section{Regional disparity in areca nut consumption}

We found 23.9 (95\% CI 23.1 to 24.8) adults were consuming areca nut at national level and 14.2\% (95\% CI 13.6 to 14.9) were consuming areca nut without tobacco (table 2). Figure 1 shows considerable variations in areca nut consumption across states and UTs of India. In many states, areca nut consumption in any form was over $40 \%$ among men (like, Uttar Pradesh, Assam Meghalaya, Mizoram and Manipur) and women (like Karnataka and all north-eastern states except Nagaland). Areca nut consumption without tobacco was largely being consumed across north-eastern states, apart from other bigger states like Karnataka (28.8\%; 95\% CI 25.6 to 32.1), Tamil Nadu (25.5\%; 95\% CI 21.9 to 29.5) and Maharashtra (20\%; $95 \%$ CI 17.0 to 22.5 ). Nearly 223.4 million people out of the total 932488000 population aged 15 and above consume areca nut in India (table 3). The distribution of areca nut users both in terms of population and 
Table 2 Prevalence (in \%) of areca nut use in different forms across states and UTs of India, GATS 2016-2017

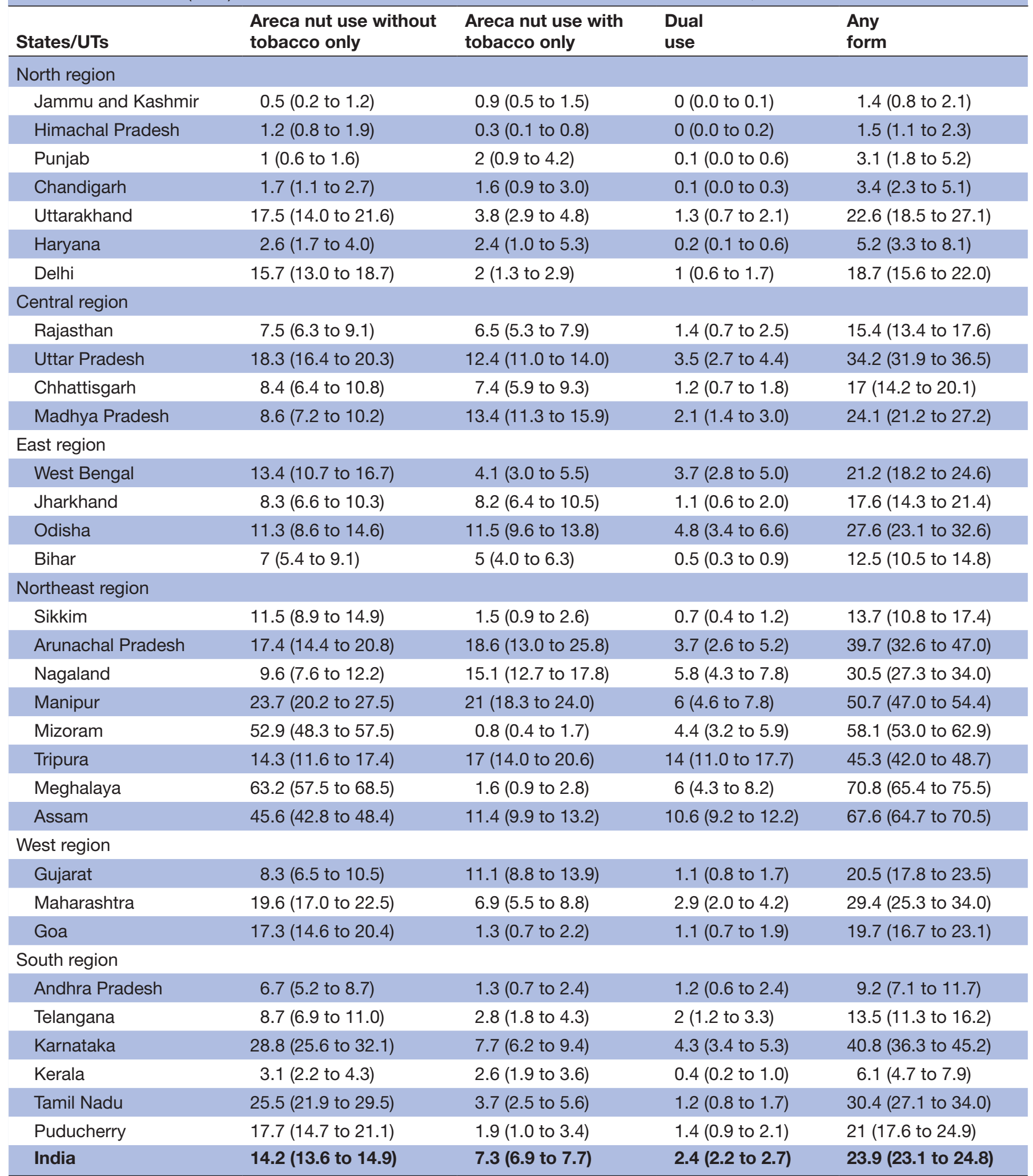

GATS, Global Adult Tobacco Survey; UTs, union territories.

proportion across states was as follows: Uttar Pradesh with 49.9 million users contributes to nearly $22 \%$ of all areca nut users, followed by Maharashtra with 26.7 million users (12\%), Karnataka with 19.8 million (9\%) and Tamil Nadu with 17.7 million users $(8 \%)$. Together, these four states share nearly $51 \%$ of all areca nut users in the country. Not much difference exists between urban and rural areas in areca nut usage patterns (online supplemental table 


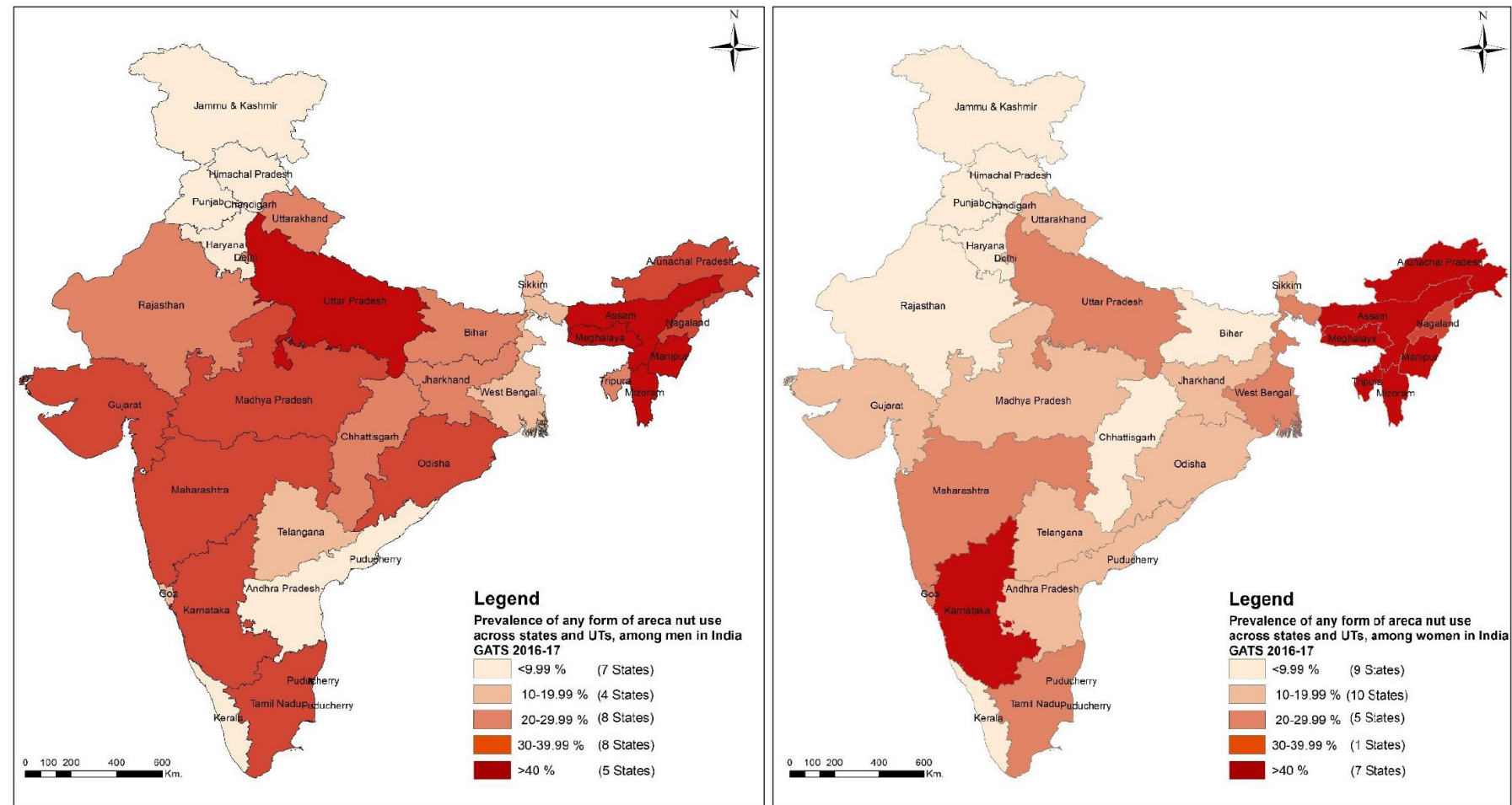

Figure 1 Geographical variation in areca nut use among adult men and women in India. GATS, Global Adult Tobacco Survey.

3). In 18 states/UTs, however, areca nut consumption was higher in urban areas than rural counterparts. In 13 states/UTs, the opposite pattern was evident.

\section{Demographic and socioeconomic differences in areca nut consumption}

Consumption of areca nut in any form was higher among men as compared with women both at national level as well as in a majority of states (online supplemental table 4). All forms of areca nut consumption were higher in the age group 31-50 years (table 4) as compared with other age categories. $28.8 \%$ men (95\% CI 27.7 to 30.0 ) and $27.1 \%$ widowed/separated/divorced (95\% CI 25.3 to 29.1) were consuming areca nut. Individuals who had completed below the primary level of schooling consumed higher proportion of areca nut. Areca nut consumption was highest among daily wage labourers $(30.2 \%$; $95 \%$ CI 28.7 to 31.7$)$. We found that a high percentage of STs $(25.6 \%$; $95 \%$ CI 23.0 to 27.5 ) and Muslims (30.8\%; $95 \%$ CI 28.4 to 33.2) were consuming areca nut.

\section{Determinants of areca nut consumption: regression analysis}

Regression results suggest that as compared with 15-18 age group, the likelihood of areca nut consumption with tobacco and dual use was higher in higher age groups (table 5); except that areca nut consumption without tobacco was lower among the age group 51 and above, as compared with the 15-18 age groups. Probability of areca nut consumption was higher among men as compared with women for all three forms. The likelihood of areca nut consumption without tobacco was higher across all the educational categories as compared with those who had no formal education. However, the probability of areca nut consumption with tobacco and in dual-form was declining with increase in the education level of respondents. The likelihood of areca nut consumption with tobacco and dual-use was significantly higher among SCs than Other castes. Probability of all the three forms of areca nut consumption was higher among Muslims as compared with Hindus.

\section{DISCUSSION}

The findings of the study revealed that nearly one out of every four adults in India consumes areca nut, that is, almost 223.79 million users, making areca nut consumption a bigger public health challenge than use of SLT (199 million users) in dealing with substance use and addiction in the country. The large number of users of areca nut, a known carcinogen, presents a huge public health challenge for the country. Moreover, nearly $10 \%$ consume areca nut with tobacco. Thus, considering the wide range of adverse health impacts, effective implementation on banning of tobacco as an ingredient with areca nut products under regulation 2.3.4 of the Food Safety and Standards Regulation, 2011 and ban on manufacture and sale of areca nut products, as implemented in some of the states, is urgently needed. ${ }^{1}$

We found considerable regional and socioeconomic differences in the consumption of areca nut. In four states, Meghalaya, Assam, Mizoram and Manipur, over half of the population consume areca nut. Furthermore, Karnataka, Uttar Pradesh, Tamil Nadu, Maharashtra and Odisha constitute nearly $55 \%$ of the country's areca nut users. As far as other determinants are concerned, 
Table 3 Population and share of areca nut use by states and UT of India, GATS 2016-2017

\begin{tabular}{|c|c|c|}
\hline States/UTs & Population & Share (in \%) \\
\hline Chandigarh & 33040 & 0.0 \\
\hline Sikkim & 68448 & 0.0 \\
\hline Himachal Pradesh & 88112 & 0.0 \\
\hline Jammu and Kashmir & 121264 & 0.1 \\
\hline Puducherry & 211680 & 0.1 \\
\hline Goa & 237779 & 0.1 \\
\hline Arunachal Pradesh & 415800 & 0.2 \\
\hline Nagaland & 459940 & 0.2 \\
\hline Mizoram & 488040 & 0.2 \\
\hline Punjab & 699081 & 0.3 \\
\hline Haryana & 1048632 & 0.5 \\
\hline Manipur & 1131624 & 0.5 \\
\hline Tripura & 1316418 & 0.6 \\
\hline Meghalaya & 1493184 & 0.7 \\
\hline Kerala & 1650843 & 0.7 \\
\hline Uttarakhand & 1756575 & 0.8 \\
\hline Delhi & 2761914 & 1.2 \\
\hline Chhattisgarh & 3262714 & 1.5 \\
\hline Andhra Pradesh & 3654056 & 1.6 \\
\hline Telangana & 3809088 & 1.7 \\
\hline Jharkhand & 4261840 & 1.9 \\
\hline Rajasthan & 7900200 & 3.5 \\
\hline Odisha & 8984904 & 4.0 \\
\hline Bihar & 9095000 & 4.1 \\
\hline Gujarat & 9813760 & 4.4 \\
\hline Madhya Pradesh & 13145827 & 5.9 \\
\hline West Bengal & 15475728 & 6.9 \\
\hline Assam & 15833272 & 7.1 \\
\hline Tamil Nadu & 17753296 & 7.9 \\
\hline Karnataka & 19834738 & 8.9 \\
\hline Maharashtra & 26753412 & 12.0 \\
\hline Uttar Pradesh & 49932289 & 22.3 \\
\hline India & 223797120 & 100.0 \\
\hline
\end{tabular}

GATS, Global Adult Tobacco Survey; UTs, union territories.

the findings confirmed that age, gender, marital status, education, occupation, castes and religion are significantly associated with areca nut consumption. However, the direction of association differs with respect to areca nut consumption with and without tobacco. Cheaper and abundant availability, due to large-scale domestic production of areca nut, could be one of the key reasons for such high prevalence in the country.

We found protective effect of secondary and above level education in the case of areca nut consumption with and without tobacco. A study from Pakistan also observed that the consumption of areca nut users increased by grade among school children aged $4-16$ years. ${ }^{27}$ Areca nut consumption was higher among men than among women, a finding that is consistent with other studies conducted in Tamil Nadu and Assam in India ${ }^{26} 35$ and countries like Thailand and Taiwan. ${ }^{13}$ It may be because areca nut consumption results in staining of teeth, which may not be liked by young and adult women. The agewise pattern suggests that areca nut consumption without tobacco began to decline from age 51 onwards. But in the case of areca nut consumption with tobacco and in both forms, it increased with age.

Similar to other studies from India and other neighbouring countries, ${ }^{24}{ }^{36}$ we also observed higher consumption of areca nut with tobacco among daily wage/ casual labourers. This study further adds that areca nut consumption without tobacco too was largely consumed by daily wage/casual labourers, followed by nongovernment sector. Evidences suggest that many misconceptions including consuming areca nut improve concentration, pleasure, helps in anxiety and muscle relaxation and suppresses appetite increases the likelihood of consumption among those who are engaged in casual labour and have long working hours. ${ }^{23} 38$ We found higher consumption of areca nut among STs and SCs than other caste groups. Furthermore, Muslims were more likely to consume all three forms of areca nut as compared with Hindus. Previous studies documented higher consumption of tobacco including SLT, among SCs/STs and Muslims. ${ }^{25} 39$

Urban-rural differences by state suggest that in 18 states, areca nut consumption was higher in urban areas than in rural areas. Regression results also revealed higher consumption of areca nut without tobacco in urban areas than rural counterparts. This is likely due to higher awareness about harms related to tobacco use in urban areas than rural counterparts. Studies from India and Pakistan documented that pan masala and gutka are very popular even in urban areas due to aggressive advertising, targeting middle class and adolescents, which improved sale many tobacco and related products including areca nut. $^{40}$

Our study had some limitations. Information related to areca nut consumption in different forms in the GATS was based on respondents self-reporting. Thus, the study cannot rule out social desirability bias—a tendency among some people to respond to questions in a way which they deem to be more acceptable than would be their 'correct' answer. ${ }^{41}$ The nomenclature of various areca nut products in geographically diverse country like India could be a source of concern, which is difficult to capture in the large-scale surveys. Considering the cross-sectional design of the survey, we did not examine the cause and effect relationship between socioeconomic characteristics and areca nut consumption. Similarly, the available data did not allow us to estimate trends of areca nut usage over time, but future analyses of repeated GATS may inform on important trends. Another limitation is that the study 
Table 4 Areca nut use pattern by demographic and socioeconomic characteristics, GATS 2016-2017

\begin{tabular}{|c|c|c|c|c|}
\hline Background variables & $\begin{array}{l}\text { Areca nut use without } \\
\text { tobacco only }\end{array}$ & $\begin{array}{l}\text { Areca nut use with } \\
\text { tobacco only }\end{array}$ & Dual use & Any forms \\
\hline & $\% 95 \% \mathrm{Cl}$ & $\% 95 \% \mathrm{Cl}$ & $\% 95 \% \mathrm{Cl}$ & $\% 95 \% \mathrm{Cl}$ \\
\hline Age & $\left(\chi^{2} p\right.$ value $\left.<0.001\right)$ & $\left(\chi^{2} p\right.$ value $\left.<0.001\right)$ & $\left(\chi^{2} p\right.$ value $\left.<0.001\right)$ & $\left(\chi^{2} p\right.$ value $\left.<0.001\right)$ \\
\hline $15-18$ & 15.7 (13.9 to 17.6$)$ & 1.9 (1.4 to 2.5$)$ & 0.7 (0.5 to 1.2 ) & 18.3 (16.5 to 20.3 ) \\
\hline $19-23$ & 14.8 (13.3 to 16.4$)$ & 5.4 (4.5 to 6.4 ) & 1.3 (0.9 to 1.9 ) & 21.5 (19.8 to 23.3$)$ \\
\hline $24-30$ & 14.1 (13.1 to 15.2$)$ & 8.2 (7.3 to 9.1$)$ & 2.4 (2.0 to 2.9 ) & 24.7 (23.3 to 26.1$)$ \\
\hline $31-40$ & 14.6 (13.6 to 15.6$)$ & 9.3 (8.6 to 10.1$)$ & 2.7 (2.4 to 3.2 ) & 26.7 (25.4 to 28.0 ) \\
\hline $41-50$ & $15.2(14.1$ to 16.3$)$ & 8.1 (7.3 to 9.0$)$ & 3.1 (2.6 to 3.7 ) & 26.4 (25.0 to 27.9 ) \\
\hline $51-60$ & 13.5 (12.2 to 14.8$)$ & 8 (7.0 to 9.0$)$ & 3.2 (2.6 to 3.9 ) & 24.6 (23.1 to 26.3 ) \\
\hline $60+$ & 11.1 (9.9 to 12.3$)$ & 7.8 (6.6 to 9.0$)$ & 3.2 (2.6 to 4.0$)$ & 22 (20.2 to 23.9 ) \\
\hline Sex & $\left(\chi^{2} p\right.$ value $\left.<0.001\right)$ & $\left(\chi^{2} p\right.$ value $\left.<0.001\right)$ & $\left(\chi^{2} p\right.$ value $\left.<0.001\right)$ & $\left(\chi^{2} p\right.$ value $\left.<0.001\right)$ \\
\hline Female & $13.2(12.5$ to 14.0$)$ & 3.4 (3.0 to 3.8$)$ & 2.3 (2.0 to 2.6$)$ & 18.9 (18.0 to 19.9$)$ \\
\hline Male & $15.2(14.4$ to 16.1$)$ & 11 (10.4 to 11.8$)$ & 2.6 (2.3 to 2.9 ) & 28.8 (27.7 to 30.0$)$ \\
\hline Marital Status & $\left(\chi^{2} p\right.$ value $\left.<0.001\right)$ & $\left(\chi^{2} p\right.$ value $\left.<0.001\right)$ & $\left(\chi^{2} p\right.$ value $\left.<0.001\right)$ & $\left(\chi^{2} p\right.$ value $\left.<0.001\right)$ \\
\hline Married & 13.7 (13.1 to 14.4$)$ & 8.1 (7.6 to 8.6$)$ & 2.7 (2.4 to 3.0 ) & 24.5 (23.6 to 25.4 ) \\
\hline Unmarried & 15.8 (14.6 to 17.1$)$ & 4.6 (3.9 to 5.3$)$ & $1(0.8$ to 1.4$)$ & 21.4 (20.0 to 22.9 ) \\
\hline $\begin{array}{l}\text { Widowed/Separated/ } \\
\text { Divorced }\end{array}$ & $14.3(12.8$ to 15.9$)$ & 8.3 (7.1 to 9.7$)$ & 4.5 (3.7 to 5.5$)$ & 27.1 (25.3 to 29.1$)$ \\
\hline Education & $\left(\chi^{2} p\right.$ value $\left.<0.001\right)$ & $\left(\chi^{2} p\right.$ value $\left.<0.001\right)$ & $\left(\chi^{2} p\right.$ value $\left.<0.001\right)$ & $\left(\chi^{2} p\right.$ value $\left.<0.001\right)$ \\
\hline No formal education & $11.2(10.3$ to 12.1$)$ & 8.7 (8.0 to 9.6$)$ & 3.7 (3.2 to 4.2$)$ & 23.6 (22.4 to 25.0$)$ \\
\hline$<$ Primary completed & $14.7(13.4$ to 16.1$)$ & 9.7 (8.6 to 10.9 ) & 2.9 (2.4 to 3.6$)$ & 27.4 (25.6 to 29.2$)$ \\
\hline Primary completed & 15.4 (14.1 to 16.9$)$ & 10 (8.9 to 11.2$)$ & 2.5 (2.0 to 3.0 ) & 27.9 (26.2 to 29.7$)$ \\
\hline$<$ Secondary completed & 16 (14.7 to 17.3$)$ & 8.5 (7.6 to 9.5$)$ & 2.4 (1.9 to 2.9 ) & 26.8 (25.3 to 28.3 ) \\
\hline Secondary completed & $15.1(13.8$ to 16.5$)$ & 5.1 (4.4 to 5.8 ) & 1.7 (1.3 to 2.4 ) & 21.9 (20.5 to 23.5$)$ \\
\hline $\begin{array}{l}\text { Higher Secondary } \\
\text { completed }\end{array}$ & $15.6(14.0$ to 17.3$)$ & 4.4 (3.6 to 5.3 ) & $1.4(0.9$ to 2.1$)$ & 21.4 (19.7 to 23.3 ) \\
\hline $\begin{array}{l}\text { College/University } \\
\text { completed }\end{array}$ & 15.5 (13.9 to 17.3$)$ & 3 (2.3 to 3.8$)$ & 1.1 (0.7 to 1.7$)$ & 19.6 (17.8 to 21.5$)$ \\
\hline $\begin{array}{l}\text { Post-graduate } \\
\text { completed }\end{array}$ & $12.8(10.7$ to 15.2$)$ & 2.8 (1.6 to 4.6$)$ & 0.9 (0.4 to 2.4$)$ & 16.5 (14.0 to 19.3$)$ \\
\hline Occupation & $\left(\chi^{2} p\right.$ value $\left.<0.001\right)$ & $\left(\chi^{2} p\right.$ value $\left.<0.001\right)$ & $\left(\chi^{2} p\right.$ value $\left.<0.001\right)$ & $\left(\chi^{2} p\right.$ value $\left.<0.001\right)$ \\
\hline Student & 14.8 (13.2 to 16.6$)$ & 0.8 (0.5 to 1.2$)$ & $0.3(0.2$ to 0.6$)$ & $15.8(14.2$ to 17.6$)$ \\
\hline Government Employee & 17.4 (14.9 to 20.3$)$ & 6.7 (5.1 to 8.8 ) & 1.9 (1.1 to 3.4$)$ & 26.1 (23.2 to 29.2$)$ \\
\hline $\begin{array}{l}\text { Non-government } \\
\text { Employee }\end{array}$ & 16.9 (15.3 to 18.6$)$ & 10.4 (8.7 to 12.3$)$ & 2.7 (2.0 to 3.8 ) & 30 (27.7 to 32.5$)$ \\
\hline $\begin{array}{l}\text { Daily Wage/Casual } \\
\text { Labourer }\end{array}$ & $15.3(14.2$ to 16.5$)$ & 11.4 (10.4 to 12.4$)$ & 3.5 (3.0 to 4.1 ) & $30.2(28.7$ to 31.7$)$ \\
\hline Self-employed & 14.9 (13.8 to 16.2$)$ & 11.7 (10.7 to 12.7$)$ & 3.1 (2.7 to 3.7 ) & 29.7 (28.2 to 31.4$)$ \\
\hline Homemaker & 12.4 (11.6 to 13.3$)$ & 3.5 (3.1 to 4.1$)$ & 1.9 (1.6 to 2.3$)$ & $17.9(16.9$ to 18.9$)$ \\
\hline Retired & 9.1 (7.2 to 11.6$)$ & 6.3 (4.1 to 9.5$)$ & 2.6 (1.2 to 5.7$)$ & 18 (14.7 to 22.0$)$ \\
\hline $\begin{array}{l}\text { Unemployed able to } \\
\text { work }\end{array}$ & 14.6 (11.9 to 17.8$)$ & 6.5 (4.6 to 9.2 ) & 2.8 (1.7 to 4.6 ) & 23.9 (20.3 to 28.0$)$ \\
\hline $\begin{array}{l}\text { Unemployed unable to } \\
\text { work }\end{array}$ & 10.7 (8.5 to 13.2$)$ & 7 (5.2 to 9.4$)$ & 3.4 (2.1 to 5.4$)$ & 21.1 (18.2 to 24.4$)$ \\
\hline $\begin{array}{l}\text { Knowledge of adverse } \\
\text { health impact of SLT use }\end{array}$ & $\left(\chi^{2} p\right.$ value $\left.<0.001\right)$ & $\left(\chi^{2} p\right.$ value $\left.<0.001\right)$ & $\left(\chi^{2} p\right.$ value $\left.<0.001\right)$ & $\left(\chi^{2} p\right.$ value $\left.<0.001\right)$ \\
\hline No & 11.5 (8.3 to 15.7$)$ & 7.7 (5.6 to 10.4$)$ & 3.7 (2.2 to 6.1$)$ & 22.9 (18.6 to 27.8$)$ \\
\hline Partial & $15.2(14.1$ to 16.3$)$ & 9 (8.2 to 9.9$)$ & 3.4 (2.9 to 3.9 ) & 27.5 (26.1 to 29.0$)$ \\
\hline Full & 14 (13.4 to 14.8$)$ & 6.8 (6.4 to 7.3 ) & 2.2 (2.0 to 2.4 ) & 23.1 (22.2 to 24.0$)$ \\
\hline
\end{tabular}


Table 4 Continued



$\chi^{2}$ p value $<0.001$

GATS, Global Adult Tobacco Survey.

is based on 15 years and older population, whereas the areca nut habits often start at younger age. The future Global Youth Tobacco Survey should have areca nutrelated questions similar to GATS, so that detailed usage pattern of areca nut could be examined among younger population of the country.

\section{CONCLUSION}

It is now well established that areca nut consumption in any form is highly addictive, a well-known risk factor for oral, pharynx and oesophageal cancers and is associated with many adverse health effects. This study adds to the existing knowledge that areca nut consumption in India was much higher than the overall SLT. Moreover, a significant proportion of areca nut was consumed along with tobacco, which elevates the adverse health impacts and comorbidities further. Thus, it calls for urgent policy intervention to prevent both new generations from taking up areca nut consumption habit and helping current users to quit. Such policy efforts to control areca nut consumption should be guided by the huge differences in its consumption across states, gender and socioeconomic groups in India. Unlike tobacco, for which the WHO FCTC provides evidence-based policies, no global policy exists for the regulation and control of areca nut consumption and its cessation. Also, there is a need for further research and population-based interventions to find treatment for areca nut dependence. In addition, research is needed to examine the intention to quit among areca nut users, separately for all three categories-those who consume areca nut with tobacco, without tobacco and those who consume in both the forms - to develop an appropriate 


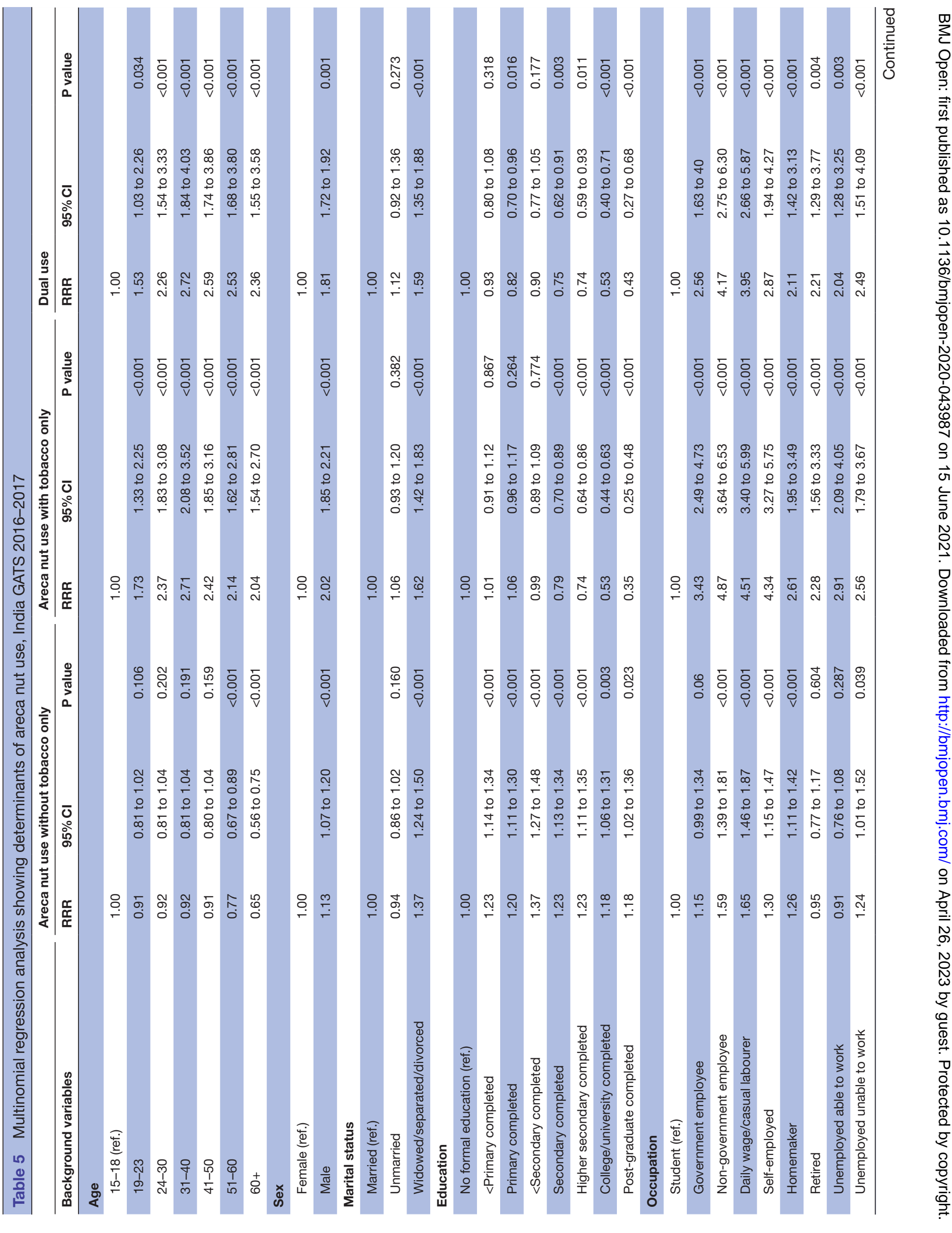




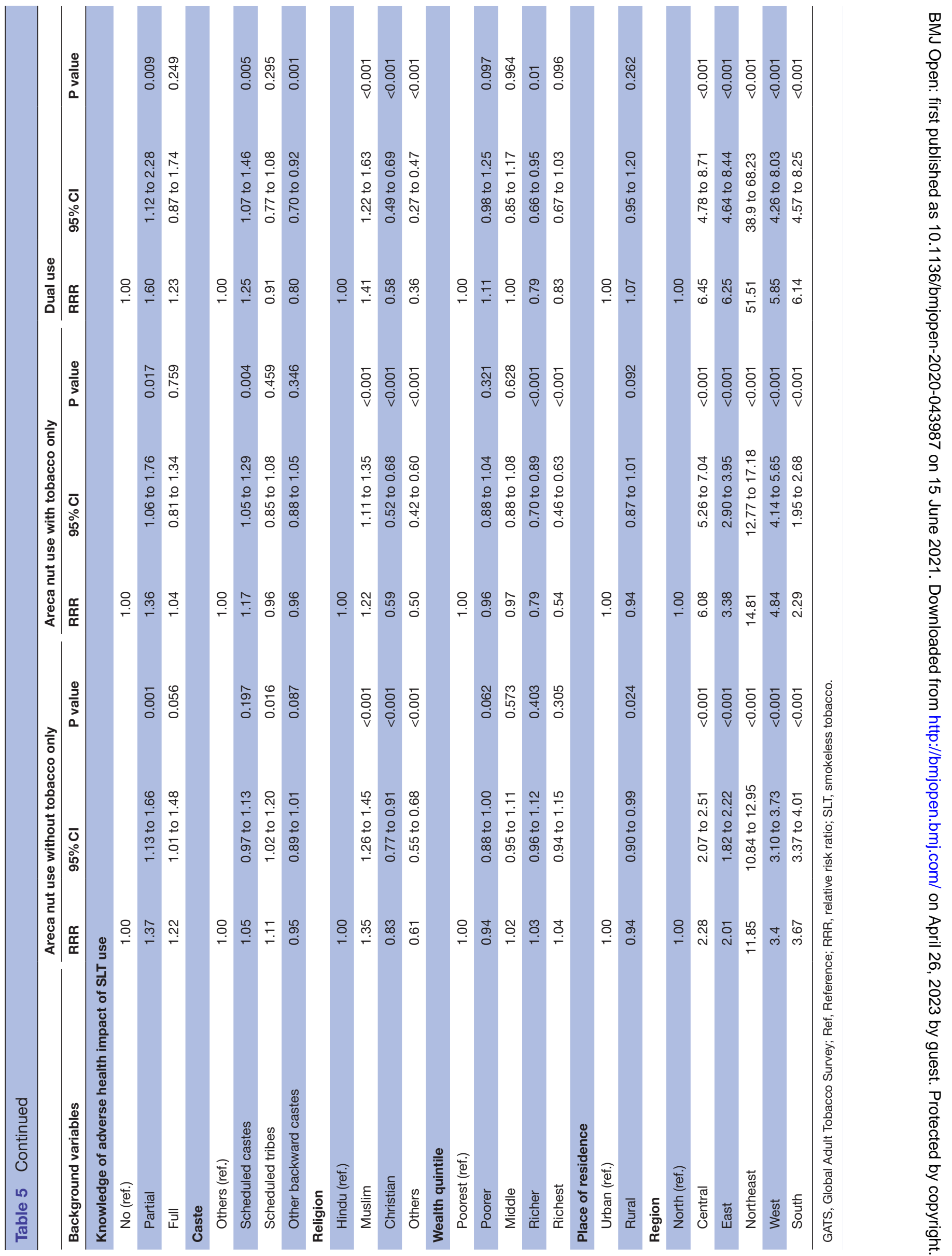


intervention model for cessation. This information may be collected within the GATS survey by adding a few additional questions on areca nut for future analysis. Given that areca nut consumption follows a complex pattern by socioeconomic status (SES) and regional trajectories, separately for with and without tobacco, future research is needed to explore the various intersections between SES and areca nut consumption in different regions of India to gain better clarity.

\section{Author affiliations}

${ }^{1}$ Division of Preventive Oncology \& Population Health, ICMR - National Institute of Cancer Prevention and Research, Noida, India

${ }^{2}$ WHO FCTC Global Knowledge Hub on Smokeless Tobacco, ICMR - National Institute of Cancer Prevention and Research, Noida, India

${ }^{3}$ The International Union Against Tuberculosis and Lung Disease (The Union) South East Asia Office, New Delhi, India

${ }^{4}$ ICMR - National Institute of Medical Statistics, New Delhi, India

${ }^{5}$ Centre for Health Economics, University of York, Heslington, York, UK

${ }^{6}$ School of Preventive Oncology, Patna, India

${ }^{7}$ Boston College USA, Boston, Massachusetts, USA

${ }^{8}$ ISGlobal, Barcelona, Spain

${ }^{9}$ ICMR - National Institute of Cancer Prevention and Research, Noida, India

Twitter Prashant Kumar Singh @prashantks_pks and Amit Yadav @ayadav24

Contributors PKS conceived the study. PKS and LS performed the statistical analysis. PKS and LS analysed and interpreted the data. PKS and AY drafted the manuscript. SM, DNS, KS and SS provided comments and contributed to the development of the final draft of the manuscript. All authors have supervised and approved the manuscript.

Funding The authors have not declared a specific grant for this research from any funding agency in the public, commercial or not-for-profit sectors.

Map disclaimer The depiction of boundaries on the map(s) in this article does not imply the expression of any opinion whatsoever on the part of BMJ (or any member of its group) concerning the legal status of any country, territory, jurisdiction or area or of its authorities. The map(s) are provided without any warranty of any kind, either express or implied.

Competing interests None declared.

Patient consent for publication Not required.

Ethics approval The second round of GATS obtained ethical clearance from the Ethics Committee of Tata Institute of Social Sciences. No ethics clearance was required for this study, as we performed a secondary analysis using publicly available data.

Provenance and peer review Not commissioned; externally peer reviewed.

Data availability statement Data are available in a public, open access repository. Data are available upon reasonable request. Data used by the study are available by emailing prashants.geo@gmail.com.

Supplemental material This content has been supplied by the author(s). It has not been vetted by BMJ Publishing Group Limited (BMJ) and may not have been peer-reviewed. Any opinions or recommendations discussed are solely those of the author(s) and are not endorsed by BMJ. BMJ disclaims all liability and responsibility arising from any reliance placed on the content. Where the content includes any translated material, BMJ does not warrant the accuracy and reliability of the translations (including but not limited to local regulations, clinical guidelines, terminology, drug names and drug dosages), and is not responsible for any error and/or omissions arising from translation and adaptation or otherwise.

Open access This is an open access article distributed in accordance with the Creative Commons Attribution Non Commercial (CC BY-NC 4.0) license, which permits others to distribute, remix, adapt, build upon this work non-commercially, and license their derivative works on different terms, provided the original work is properly cited, appropriate credit is given, any changes made indicated, and the use is non-commercial. See: http://creativecommons.org/licenses/by-nc/4.0/.

\section{ORCID iDs}

Prashant Kumar Singh http://orcid.org/0000-0003-1742-5534
Sumit Mazumdar http://orcid.org/0000-0002-9278-4396

\section{REFERENCES}

1 Gupta PC, Ray CS, Papke RL, et al. Perspectives on areca nut with some global implications: symposium report. Translational Research in Oral Oncology 2018;3:2057178X1881406.

2 Warnakulasuriya S, Peters TJ. Introduction: biology, medical and socio-economic aspects of areca nut use. Addict Biol 2002;7:75-6.

3 Mehrtash H, Duncan K, Parascandola M, et al. Defining a global research and policy agenda for betel quid and areca nut. Lancet Oncol 2017:18:e767-75.

4 National Institute of Cancer Prevention and Research (ICMR). Commonly used smokeless tobacco products around the globe, 2020. Available: https://untobaccocontrol.org/kh/smokelesstobacco/paan-betel-quid-tobacco/

5 Patidar KA, Parwani R, Wanjari SP, et al. Various terminologies associated with areca nut and tobacco chewing: a review. J Oral Maxillofac Pathol 2015;19:69.

6 IARC Working Group on the Evaluation of Carcinogenic Risks to Humans. Betel-quid and areca-nut chewing and some areca-nut derived nitrosamines. IARC Monogr Eval Carcinog Risks Hum 2004:85:1-334.

7 Guha N, Warnakulasuriya S, Vlaanderen J, et al. Betel quid chewing and the risk of oral and oropharyngeal cancers: a meta-analysis with implications for cancer control. Int J Cancer 2014;135:1433-43.

8 Garg A, Chaturvedi P, Gupta PC. A review of the systemic adverse effects of areca nut or betel nut. Indian J Med Paediatr Oncol 2014;35:3.

9 Mirza SS, Shafique K, Vart P, et al. Areca nut chewing and dependency syndrome: is the dependence comparable to smoking? A cross sectional study. Subst Abuse Treat Prev Policy 2011;6:23.

10 Papke RL, Horenstein NA, Stokes C. Nicotinic activity of arecoline, the psychoactive element of "Betel Nuts", suggests a basis for habitual use and anti-inflammatory activity. PLOS One 2015;10:e0140907.

11 Chandra PS, Mulla U. Areca nut: the hidden Indian 'gateway' to future tobacco use and oral cancers among youth. Indian J Med Sci 2007;61:319-21.

12 Mehrotra R, Yadav A, Sinha DN, et al. Smokeless tobacco control in 180 countries across the globe: call to action for full implementation of WHO FCTC measures. Lancet Oncol 2019;20:e208-17.

13 Gupta PC, Warnakulasuriya S. Global epidemiology of areca nut usage. Addict Biol 2002;7:77-83.

14 James KS. India's Demographic Change: Opportunities and Challenges. Science 2011;333:576-80.

15 Singh PK, Yadav A, Lal P. Dual burden of smoked and smokeless tobacco use in India, 2009-2017: a repeated cross-sectional analysis based on global adult tobacco survey. Nicotine Tob Res 2020.

16 Singh PK. Trends in child immunization across geographical regions in India: focus on urban-rural and gender differentials. PLoS One 2013;8:e73102

17 Subramanian SV, Nandy S, Irving M, et al. The mortality divide in India: the differential contributions of gender, caste, and standard of living across the life course. Am J Public Health 2006;96:818-25.

18 Kumar C, Singh PK, Rai RK. Under-five mortality in high focus states in India: a district level geospatial analysis. PLoS One 2012;7:e37515.

19 Farahani M, Subramanian SV, Canning D. Effects of state-level public spending on health on the mortality probability in India. Health Econ 2010;19:1361-76.

20 Kravdal Øystein. Child mortality in India: the community-level effect of education. Popul Stud 2004;58:177-92.

21 TISS, MoHFW. Global adult tobacco survey GATS 2 India 2016-17. New Delhi, India, 2017.

22 Tata Institute of Social Sciences and Ministry of Health and Family Welfare Government of India. Global adult tobacco survey GATS 2 India 2016-2017 report, 2017. Available: https://untobaccocontrol. org/kh/smokeless-tobacco/wp-content/uploads/sites/6/2018/06/ GATS_.pdf

23 Ansari ZA, Bano SN, Zulkifle M. Prevalence of tobacco use among power loom workers - a cross-sectional study. Indian J Community Med 2010;35:34.

24 Bandyopadhyay A, Irfan M. Educational and wealth inequalities in smokeless tobacco use: an analysis of rural-urban areas of Bangladesh and India. Subst Abuse 2019;13:117822181882507.

25 Bhan N, Karan A, Srivastava S, et al. Have socioeconomic inequalities in tobacco use in India increased over time? trends from the national sample surveys (2000-2012). Nicotine Tob Res 2016;18:1711-8. 
26 Rajan G, Ramesh S, Sankaralingam S. Areca nut use in rural Tamil Nadu: a growing threat. Indian J Med Sci 2007;61:332-7.

27 Shah SMA, Merchant AT, Luby SP, et al. Addicted schoolchildren: prevalence and characteristics of areca nut chewers among primary school children in Karachi, Pakistan. J Paediatr Child Health 2002;38:507-10.

28 Rutstein SO, Johnson K. The DHS wealth index. DHS Comp. Reports 2004;6. No.http://dhsprogram.com/pubs/pdf/CR6/CR6. pdf

29 Filmer D, Pritchett LH. Estimating wealth effects without expenditure data--or tears: an application to educational enrollments in states of India. Demography 2001;38:115-32.

30 Borooah VK. Caste, religion, and health outcomes in India, 2004-14. Econ Polit Wkly 2018;53:65.

31 Desai S, Dubey A. Caste in 21st century India: competing narratives. Econ Polit Wkly 2012;46:40.

32 Scott Long J. Regression models for categorical and limited dependent variables. 7. USA: Indiana University, 1997.

33 Haan P, Uhlendorff A. Estimation of multinomial logit models with unobserved heterogeneity using maximum simulated likelihood. Stata J 2006;6:229-45.
34 Stata S. Release 15. statistical software. Coll Station TX: StataCorp LP, 2017.

35 Mahanta B, Phukan N, Mohapatra PK. Betel nut chewing habit and its determinants among adolescent boys and girls in an industrial town of Assam, India. International Journal of Health Sciences and Research.

36 Hashibe M, Jacob BJ, Thomas G, et al. Socioeconomic status, lifestyle factors and oral premalignant lesions. Oral Oncol 2003;39:664-71.

37 Gunaseelan R, Sankaralingam S, Ramesh S, et al. Areca nut use among rural residents of Sriperambudur Taluk: a qualitative study. Indian J Dent Res 2007;18:11.

38 Thankappan KR, Thresia CU. Tobacco use \& social status in Kerala. Indian J Med Res 2007;126:300.

39 Rani Met al. Tobacco use in India: prevalence and predictors of smoking and chewing in a national cross sectional household survey. Tob Control 2003;12:4e-4.

40 Tobacco Free Initiative, World Health Organization. Tobacco and youth in the South East Asian region. Indian J Cancer 2002;39:5-34.

41 Fisher RJ. Social desirability bias and the validity of indirect Questioning. J Consum Res 1993;20:303-15. 